\title{
Nicotiana tabacum Mediated Green Synthesis of Silver Nanoparticles and Ag-Ni Nanohybrid: Optical and Antimicrobial Efficiency
}

\author{
Anuoluwa Abimbola Akinsiku, ${ }^{1 *}$, Joseph Adeyemi Adekoya ${ }^{1}$, and Enock Olugbenga Dare ${ }^{2, * *}$ \\ ${ }^{1}$ Department of Chemistry, College of Science and Technology, Covenant University, Canaanland, Km 10 Idiroko Road, \\ P.M.B. 1023, Ota, Ogun State, Nigeria \\ ${ }^{2}$ Department of Chemistry, Federal University of Agriculture Abeokuta, Alabata Road, P.M.B. 2240, Abeokuta, Ogun State, Nigeria
}

\begin{abstract}
* Corresponding author:
email:

anu.akinsiku@covenantuniversity.edu.ng*;

dare3160@hotmail.com ${ }^{* *}$

Received: May 13, 2020

Accepted: June 18, 2020

DOI: $10.22146 / \mathrm{ijc} .56072$

Abstract: A sustainable method was considered for the preparation of nanosilver and its allied nanoparticles. Nicotiana tabacum, an abused plant, has found an application as a bio-chemical instead of lethal chemical in the synthesis of nanoparticles. As part of green chemistry implementation, double distilled water was the solvent used for extraction. The phytochemicals present were analyzed using standard procedures. Nanoparticle synthesis was carried out at varying precursor concentrations, and the reaction was monitored with a UV-visible spectrophotometer. Another optical characterization was also achieved with photoluminescence. Other characterization involved: X-ray diffraction (XRD), transmission electron microscopy (TEM), energy dispersive X-ray (EDS), and Fourier transform infrared spectroscopy techniques (FTIR). A matched phase identification of nanosilver resembled a face-centered cubic of $\mathrm{Ag}$ with a mean size of $11.68 \mathrm{~nm}$, and a lattice constant of $4.0862 \AA$. The Ag NPs displayed activity against clinical isolates of fungi, Gram-positive, and Gram-negative bacteria as the growth inhibition was significant at $P<0.05$. Ag NPs obtained from the Nicotiana tabacum proved to be an antibacterial and antifungal candidate, unlike the Ag NPs derived using chemical and physical methods, which were harmful for this purpose. Both the Ag NPs and Ag-Ni NPs displayed optical activity, which qualifies them for application in visual materials.
\end{abstract}

Keywords: green synthesis; optical properties; antimicrobial; Nicotiana tabacum

\section{- INTRODUCTION}

Great use of nanoparticles (NPs) and nanomaterials (NMs) in the last decade is on the rise across the fields of science and technology. Materials with sizes of less than $100 \mathrm{~nm}$ have been proven to possess enhanced structural features that equip them with excellent properties such as enhanced optical, surface activity, magnetic and electrical properties. These materials are further developed for applications in cancer diagnosis (medicine), pharmaceuticals, battery electrodes, communication technology (use of carbon nanotubes), textile, food industries, etc. [1]. It is of note that physical and chemical methods of producing nanoparticles and nanomaterials involve the use of toxic chemicals, and these protocols pose a threat to the environment and human health.
Moreover, the procedures are costly, while the products are hardly appropriated for medicine [2-3]. Hence, the application of green chemistry in nanotechnology is considered an alternative to overcome earlier mentioned problems.

Microorganisms, plants, and plant extracts are often utilized in place of chemicals for the biosynthesis of nanoparticles and nanomaterials. Furthermore, plant-mediated synthesis is of many advantages, like sustainability and renewability of plant materials, which are the sources of secondary metabolites - the reducer. The protocol is also nature-friendly, cost-effective, rapid, etc. Metal ion reduction is possible by plant extracts due to the presence of chemicals and bioactive compounds (phytochemicals) naturally present in them, 
most notably the medicinal plants. $N$. tabacum has been identified to contain phenolic compounds, terpenoids, essential oils, and alkaloids, which includes an $\mathrm{N}$-methyl group [4]. These active functional groups in N. tabacum qualifies it as a metal ion reducer for the formation of nanoparticles.

Nicotiana tabacum (Tobacco) is an annual herb, and it belongs to the Solanaceae family. It is known as 'ewe taba' by the Yoruba tribe in Nigeria, and it can grow to a maximum height of 3 meters. $N$. tabacum possesses green leaves that are commercially processed into tobacco [5]. The plant is ornamental and also secrets nicotine. Its ethnobotanical use includes treatment of ringworm, cold, ulcers, nausea, anthelmintic, hemorrhoids (pile), dysmenorrhea, hair fertilizer, etc. [6-7]. The large amount of toxins in tobacco makes it useful in the manufacture of insecticides. It also finds an application in medicine. Unfortunately, it is abused for chronic smoking, and this addictive effect is dangerous to health [8].

Many studies have reported silver-based nanoparticles using green synthesis. Recent publications exploited the use of bio-reducing agents like ulvan from green algae [9], Withania coagulans [10], Annona reticulata leaves [11], Origanum vulgare plant [12], Canna indica plant [13], etc. for various applications. Synthesis of Ag-Ni nanoparticles involving physical and chemical methods like flame synthesis [14], chemical-wet approach [15], solvothermal [16], etc., were also documented. However, to the best of our knowledge, not much work regarding the plant-mediated green synthesis of Ag NPs and Ag-Ni NPs using tobacco as a renewable reducing agent has been published. Furthermore, since the mechanism of the reaction of nanoparticles as an antimicrobial agent does not require penetrating the cell walls of bacteria, the problem of drug resistance in bacteria due to large applications could be tackled via this synthetic route. In addition, silver-based nanoparticles have been proven to be able to overcome biofilm formation, one of the antibiotics resistance mechanisms [17]. This study focused on the exploitation of N. tabacum for silver and its hybrid nanoparticles with potential optical and antimicrobial applications. The antimicrobial properties of the synthesized nanoparticles were tested on Gramnegative bacteria, Gram-positive bacteria, and fungi.

\section{- EXPERIMENTAL SECTION}

\section{Materials}

The N. tabacum used in this study was obtained from the university campus. The plant was bioauthenticated, and a voucher FHI. No.109929 was deposited at the herbarium. Analytical grade of all inorganic salts and reagents, which include $\mathrm{AgNO}_{3}$, and $\mathrm{Ni}\left(\mathrm{NO}_{3}\right)_{2} \cdot 6 \mathrm{H}_{2} \mathrm{O}$ (Sigma-Aldrich, UK), were used. Double distilled water was used throughout the preparations, and for the rinsing of leaves for the removal of sand.

\section{Instrumentation}

\section{Sample characterization}

For the optical study, the absorption spectra were obtained from a double beam (Thermos Scientific Genesys 10S) spectrophotometer. Perkin-Elmer 55 luminescence spectrophotometer was used for the photoluminescence of the particles. Double distilled water was used as blank, and samples were prepared by diluting each aliquot to one fifth, then placed in the quartz cuvette at $25^{\circ} \mathrm{C}$. The absorption was measured at 200-800 nm. For the morphological characterization of the biosynthesized nanoparticles, the transmission electron microscopy technique was engaged. Measurements were achieved with a Technai G2 microscope attached with an energy dispersive $\mathrm{x}$-ray spectrometer, ran at a current of $20 \mu \mathrm{A}$ and accelerated voltage of $200 \mathrm{keV}$. A drip of each nanoparticle solution was positioned on copper TEM grids covered with carbon. The solution was allowed to dry by evaporation, after which snapshots were taken. For structural analysis and purity of the as-prepared nanoparticles, XRD (Bruker AXS D8 model) equipped with nickel $\mathrm{Cu} \mathrm{Ka}$ radiation source at room temperature from $20^{\circ}$ to $80^{\circ}$ at $40 \mathrm{kV}$, $40 \mathrm{~mA}, \mathrm{k}=1.5418 \AA$ and scanning rate of $0.050 \mathrm{~min}^{-1}$ was used. The moieties present in the nanoparticles were determined with FTIR (Perkin Elmer 100). Centrifugation was carried out with Thermo Fisher scientific centrifuge (Thermo Electron LED). 


\section{Procedure}

Extraction was achieved by modifying the method described in our previous works $[12,18]$. The leaves were cut, ground with a clean blender, and then subjected to extraction at the weight $(20 \mathrm{~g})$ to volume $(200 \mathrm{~mL})$ ratio. The slurry formed was separated with Whatman filter paper (no. 1) at ambient temperature. The filtrate was reserved in the refrigerator for analysis and use. A qualitative study to determine secondary metabolites in the aqueous extract of $N$. tabacum was carried out using a standard method [19].

\section{Preparation of silver and silver-nickel nanoparticles by $N$. tabacum}

For the synthesis of silver nanoparticles (Ag NPs), an aqueous solution of $N$. tabacum leaf extract $(40 \mathrm{~mL})$ was introduced into $0.5 \mathrm{mM}$ aqueous solution of $\mathrm{AgNO}_{3}$ $(400 \mathrm{~mL})$ in a beaker, heated up to $80{ }^{\circ} \mathrm{C}$ on a magnetic stirrer for $40 \mathrm{~min}$. This procedure was used again for different ratios of metal ion concentrations (1.0, 2.0, and $3.0 \mathrm{mM}$ ) and extract at a $1: 10 \mathrm{v} / \mathrm{v}$ ratio. The reaction mixture was monitored for color change (notification of nanoparticle formation), confirmed by UV-visible spectroscopy measurement of the samples taken at various time intervals. To separate and purify the as-prepared nanoparticles, centrifugation was performed at 5000 revolutions/min for $45 \mathrm{~min}$. The samples were later thoroughly washed in double distilled water, evaporated, then collected for characterization and antimicrobial study. In the case of nanohybrid synthesis, an aqueous extract of $N$. tabacum was poured to the mixture of equal molar concentrations of $\mathrm{AgNO}_{3}$ and $\mathrm{Ni}\left(\mathrm{NO}_{3}\right)_{2} \cdot 6 \mathrm{H}_{2} \mathrm{O}$ in $1: 10 \mathrm{v} / \mathrm{v}$ ratio. Then, the procedure mentioned above was repeated using 1.0 and $2.0 \mathrm{mM}$ precursor mixture solutions.

\section{Antimicrobial assay}

Fresh isolates of fungi Trichophyton rubrum and Candida albicans, Gram-positive Streptococcus pyogenes and Staphylococcus aureus and Gram-negative Pseudomonas aeruginosa and Escherichia coli bacteria were used as the test organisms. The experiment was conducted at the Department of Medical Microbiology and Parasitology of Sacred Heart Hospital, Abeokuta, Nigeria.
0.5 McFarland turbidity standard. In preparing turbidity for inocula, the British Society for Antimicrobial Chemotherapy (BSAC) procedure was followed. For the standardization of the organisms, 0.5 McFarland standard was developed using laboratory guidance- $\left(0.5 \mathrm{~mL}\right.$ of $0.048 \mathrm{M} \mathrm{BaCl}_{2}\left(1.175 \% \mathrm{w} / \mathrm{v} \mathrm{BaCl} \mathrm{Ba}_{2}\right.$ in $2 \mathrm{H}_{2} \mathrm{O}$ ) was added to $99.5 \mathrm{~mL}$ of $0.18 \mathrm{M} \mathrm{H}_{2} \mathrm{SO}_{4}$ with constant stirring to maintain a suspension). An acceptable standard is between $0.08-0.13$ for 0.5 McFarland standard $\left(1.5 \times 10^{8}\right.$ bacterial cell per $\left.\mathrm{mL}\right)$. Afterwards, the density of the turbidity was confirmed with a UV-vis spectrophotometer (T90+ model) operated at wavelength of $625 \mathrm{~nm}$. The prepared standard was then evenly distributed into screw cap test tubes, firmly closed, and then kept in the dark at $25^{\circ} \mathrm{C}$ [20].

Mueller Hinton broth $(5 \mathrm{~mL})$ containing strains of the isolates (inocula) was dispensed into each screwcapped test tube and sterilized in an autoclave for $15 \mathrm{~min}$ at $121^{\circ} \mathrm{C}$. After cooling, the test tubes were kept inside an incubator for $24 \mathrm{~h}$ at $37^{\circ} \mathrm{C}$ to ensure sterility. The pathogenic isolates were then inoculated into the sterilized test tubes containing medium and incubated overnight at $3{ }^{\circ} \mathrm{C}$. The apparent turbidity in the broth culture was adjusted to $0.5 \mathrm{McF}$ arland (standard) by adding sterile normal saline. Hence, the $0.5 \mathrm{McF}$ arland standard produced turbidity equivalent to a bacterial suspension containing $1.5 \times 10^{8} \mathrm{cfu} / \mathrm{mL}$. The suspension was used within $5 \mathrm{~min}$ to avoid population increase [21]. The sensitivity of test organisms. The sensitivity of the test organisms on the prepared nanoparticles was investigated using a modified procedure by Aida, as recommended by the National Committee for Clinical Laboratory Standards (NCCLS). Sterile agar slant was used to collect the test organisms, incubated at $37^{\circ} \mathrm{C}$ for $24 \mathrm{~h}$. Afterwards, the following biochemical analyses gram staining, sugar fermentation, gelatin liquefaction, capsule staining, citrate utilization, motility, oxidase reaction, indole test, urease test, and hydrogen test were carried out on the isolated bacteria. Sugar fermentation, gram staining, and germ test tube were used to identify Candida albicans. In contrast, macroscopic and microscopic techniques using lactophenol cotton blue 
stains were used to distinguish Trichophyton rubrum fungus. The stock culture was then stored and agar well diffusion procedure was used to check the antibacterial activity of the $\mathrm{Ag}$ and $\mathrm{Ag}-\mathrm{Ni}$ nanoparticles at $4{ }^{\circ} \mathrm{C}$ as described by Portillo et al. [22].

The as-prepared microbial cultures were inoculated on a $9 \mathrm{~cm}$ diameter Mueller Hinton agar plate and then flooded with $1 \mathrm{~mL}$ of each standardized test organism. Wells of $6 \mathrm{~mm}$ diameter were dug into the agar plate with a sterile cork borer. Afterwards, $0.1 \mathrm{~mL}$ of $100 \mathrm{mg} / \mathrm{mL}$ nanoparticles (constituted in 50\% DMSO) was introduced to each of them. Ciprofloxacin and fluconazole were the positive controls for bacteria and fungi, respectively. Test control $(0.1 \mathrm{~mL}$ of $5 \mu \mathrm{g} / \mathrm{mL})$ was also initiated on the agar plate in duplicates. The plates were incubated at $37^{\circ} \mathrm{C}$ for $24 \mathrm{~h}$ for bacteria and yeast, while T. rubrum was incubated at $28^{\circ} \mathrm{C}$ for $72 \mathrm{~h}$. Antibacterial activity of the nanoparticles was determined by measuring the zones of inhibition around each well on the agar plate in millimeters (excluding the diameter of the well). This procedure was done in duplicates.

Furthermore, Minimum Inhibitory Concentration (MIC) was determined using a tube dilution method. Ten (10) sterilized test tubes were organized in a rack, then sterile nutrient broth ( $1 \mathrm{~mL}$ each) was introduced into the test tubes 2 to 8 . Then, a serial doubling dilution was made to tubes 2 to 8 , disposing of the last $\mathrm{mL}$ of the broth. Ciprofloxacin $(1 \mathrm{~mL})$ was added to tube 9 , and doubledistilled water to tube 10 as a negative control. A mix of $1 \mathrm{~mL}$ of McFarland and $1 \mathrm{~mL}$ broth culture were added to each test tube; covered, left overnight, and incubated at $37{ }^{\circ} \mathrm{C}$. The experiment was monitored for the highest dilution with no turbidity. The zone of inhibition and MIC was determined using the Clinical and Laboratory Standards Institute guidelines [23].

Minimum Bactericidal Concentration (MBC) and the Minimum Fungicidal Concentration (MFC) were also determined using a revised method by Doughari [24]. For the determination of $\mathrm{MBC}, 0.5 \mathrm{~mL}$ of the sample from the MIC test, which showed no visible sign of growth, was taken and inoculated on sterile Mueller Hinton agar by streaking. In the case of MFC, $0.5 \mathrm{~mL}$ of the sample with no noticeable growth from the MIC test was taken and inoculated on sterile potato dextrose agar by streaking. Both plates were incubated at $37{ }^{\circ} \mathrm{C}$ for $24 \mathrm{~h}$. The concentration at which no visible growth was observed was recorded as the MBC and MFC after each inoculation.

\section{- RESULTS AND DISCUSSION}

From the UV-visible spectroscopy analysis, Fig. 12 reveal the combined surface plasmon resonance (SPR) bands and collective oscillations of conduction band electrons of the Ag NPs and Ag-Ni NPs [25]. The transitions, $\pi \rightarrow \pi^{*}$ (C=C in the alkaloids), and $\mathrm{n} \rightarrow \pi^{*}$ (O-H, C-O in carbohydrate and glycosides), as supported by the FTIR spectra (Fig. 5), confirmed the moieties present in the green synthesized nanoparticles. These functional groups were considered to be responsible for capping and stabilizing the newly formed nanocluster.

Evidence of nanoparticle formation was a change in color from light green to dark brown. However, there was no indication of nanoparticle formation in the reaction between the $1.0 \mathrm{mM} \mathrm{AgNO}_{3}$ solution and the

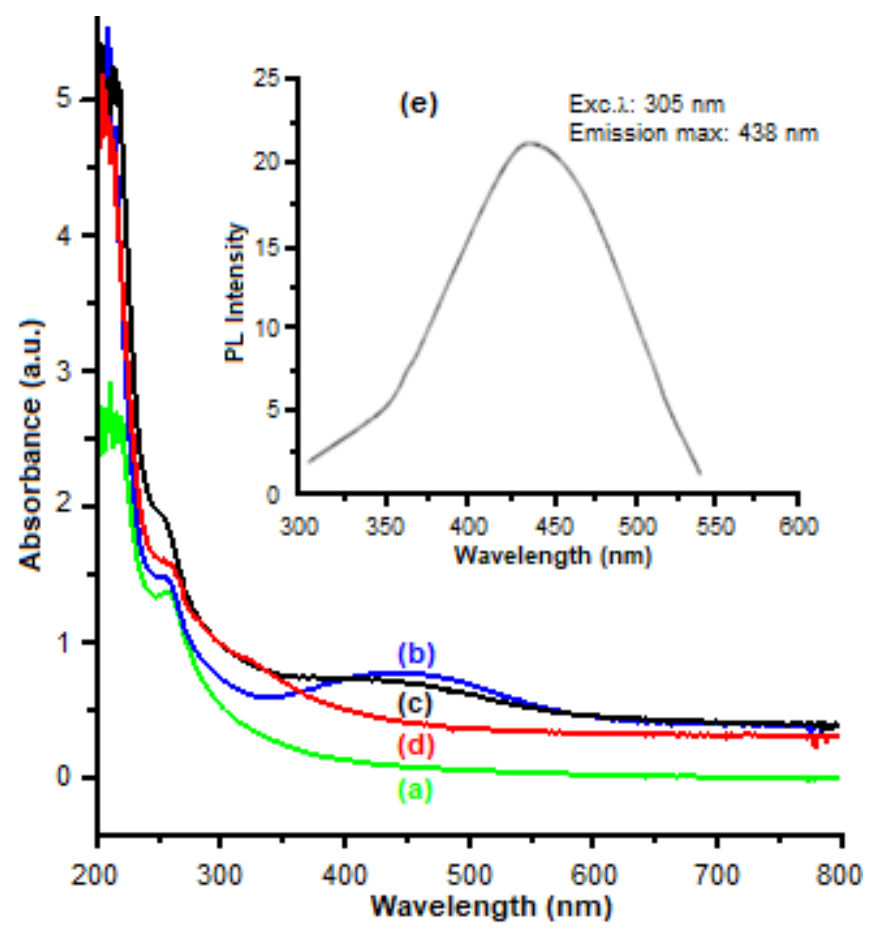

Fig 1. Absorption spectra (a) $1.0 \mathrm{mM}$ (b) $2.0 \mathrm{mM}$ (c) 3.0 $\mathrm{mM}$ (d) extract (e) inset Photoluminescence emission spectrum of Ag NPs at $40 \mathrm{~min}, 80^{\circ} \mathrm{C}$ 


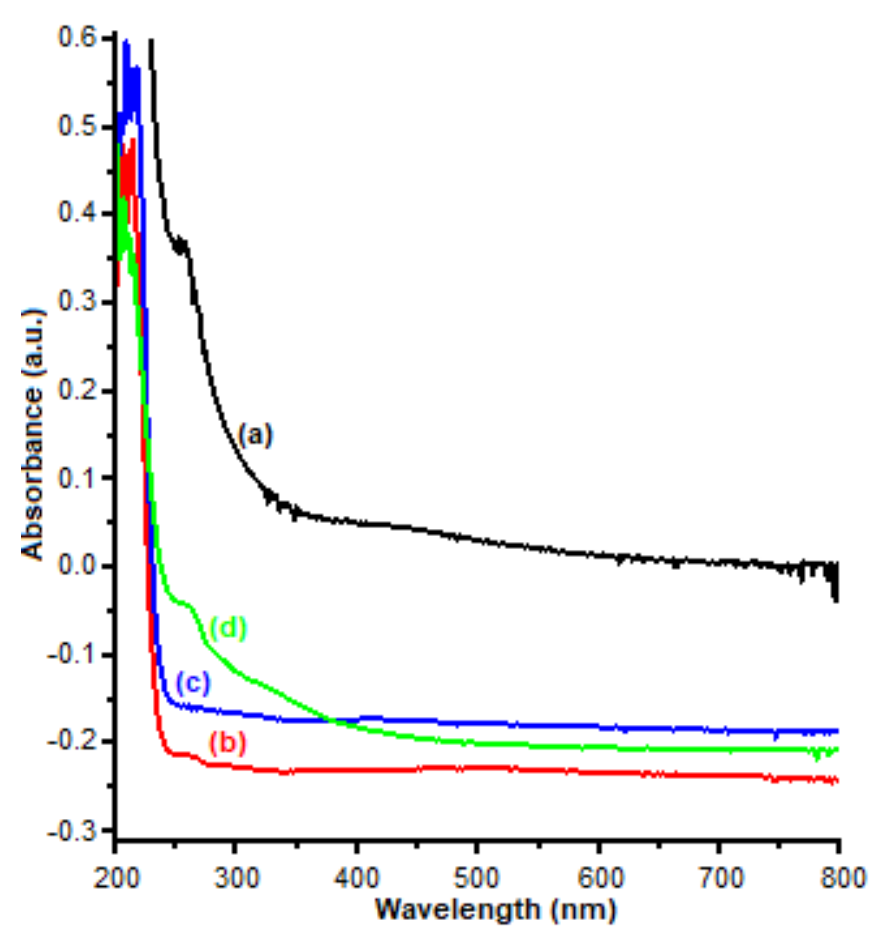

Fig 2. Absorbance spectra of Ag-Ni NPs (a) $1.0 \mathrm{mM}$ (b) $2.0 \mathrm{mM}$ (c) $3.0 \mathrm{mM}$ (d) extract at $40 \mathrm{~min}, 80^{\circ} \mathrm{C}$

extract due to the absence of SPR. This occurence could be due to the low concentration of precursors for the extract to reduce and nucleate the $\mathrm{Ag}$ ion. This finding is similar to the results of Fernando and Zhou [26]. Nucleation and onset growth occured rapidly, as early as 5 min into the reaction involving 2.0 and $3.0 \mathrm{mM}$ metal solutions, which is one of the advantages of 'green' synthesis of nanoparticles (See supplementary Fig. S1). Fig. 1 shows that the reaction mixture of silver nitrate solution $(2.0 \mathrm{mM})$ and the metabolites were considered to be the optimum condition for Ag NPs using N. tabacum as reducing agent, as the SPR increased in peak intensity at $450 \mathrm{~nm}$, which is the characteristic band for Ag NPs. The shape of the spectrum also connotes proximity to unity in the aspect ratio of as-synthesized NPs.

In the case of silver hybrid nanoparticles, the reduction of silver ions by $N$. tabacum commenced as early as $5 \mathrm{~min}$ at all the precursor solution concentrations. There is no doubt that the nucleation and growth occured rapidly, as indicated by the early appearance of SPR, suggesting that the bio-reducing agent used was adequate for the reduction process (See supplementary Fig. S2). However, the SPR bands formed were of low extinction coefficient intensity: $0.05,0.06$ and 0.07 a.u. for 1.0, 2.0 and $3.0 \mathrm{mM}$ concentrations, respectively. A peak widthbroadening was observed in the nanohybrid prepared from $2.0 \mathrm{mM}$ precursor solution (Fig. 2), compared to the corresponding Ag NPs in Fig. 1. The redshift and reduction in the SPR peak intensity might be due to the presence of nickel, and the effect of aggregation between nanoclusters, which led to the particle size increase, corroborated by the previous model [27] (See supplementary Fig. S2). Moreover, the characteristic absorbance of the nanohybrid suggests $\mathrm{Ag}_{\text {core }} \mathrm{Ni}_{\text {shell }}$ formation. The observed absorption spectra also indicated that $\mathrm{Ag}$ NPs with a characteristic peak between 400-450 $\mathrm{nm}$ are not the shell, but the core of the nanohybrid, while $\mathrm{Ni}$ formed the shell as further corroborated by the EDX (See supplementary Fig. S4) and XRD patterns. The intensity of absorbance was higher in monosilver nanoparticles compared to its allied nanoparticles. Absorption spectra comparing growth of Ag NPs and Ag-Ni NPs are shown in Fig. 1 and 2, respectively. Photoluminescence study carried out on the as-prepared Ag NPs displayed quantum yield during vibrational relaxation at triple excited state as shown in Fig. 1 (Inset e). Excitation took place at $305 \mathrm{~nm}$, and this resulted in the low intensity of emission with a single peak at $438 \mathrm{~nm}$.

The phase analysis and crystalline nature of the AgNi NPs, that was prepared using N. tabacum leaf extract as a reducing agent, were studied with $\mathrm{X}$-ray diffraction (XRD). XRD pattern of the as-prepared nanohybrid is depicted in Fig. 3(a). The diffraction peak patterns indicate the formation of alloy Ag-Ni bimetallic nanoparticles. Match phase identification is presented in Fig. 3(b). Composition of the nanoalloy resembles a face-centered cubic phase of Ag with reflection peaks at $2 \theta$ values of $37.96^{\circ}$ [111], $44.10^{\circ}$ [200], 62.44 ${ }^{\circ}$ [220] and $77.56^{\circ}$ [311]. However, there is a small deviation from the actual $2 \theta$ angles as a result of lattice insertion of $\mathrm{Ni}$ in the Ag crystal lattice, and this suggests alloying of the nanohybrid, which agrees with previous studies [28-29]. A characteristic peak of $\mathrm{Ni}$ at $2 \theta=46.24^{\circ}$ is shown. There is an overlapping peak for the (111) plane of $\mathrm{Ni}$ with that of Ag plane at $2 \theta$ $=46.24^{\circ}$, but no crystalline phase of $\mathrm{Ni}\left(52.1^{\circ}\right)$ was detected 

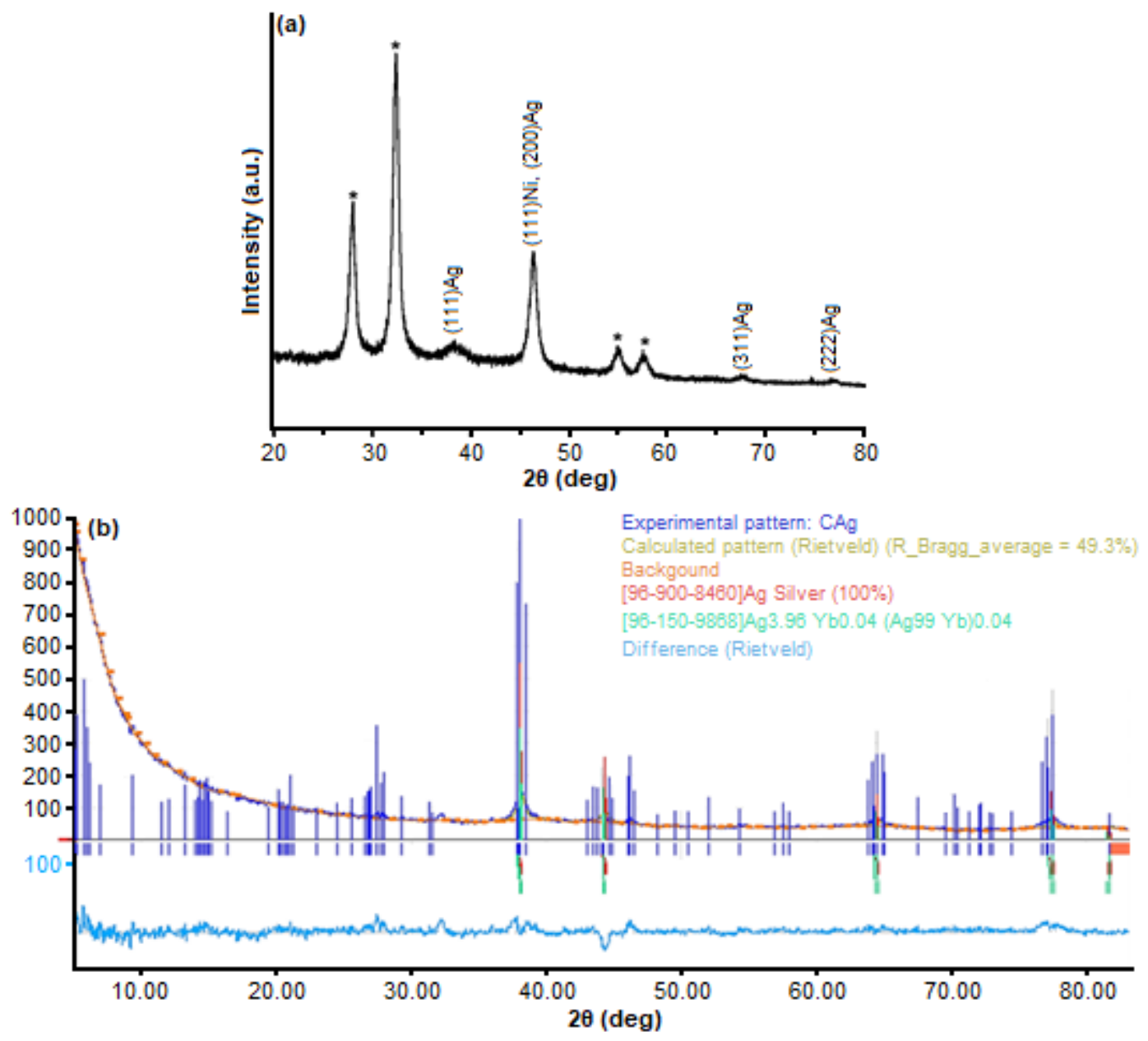

Fig 3. (a) XRD pattern of Ag-Ni NPs synthesized using N. tabacum (b) Phase matching

Table 1. Structural parameters of Ag-Ni nanohybrid

\begin{tabular}{ccccccc}
\hline $\begin{array}{c}\text { Miller } \\
\text { indices (hkl) }\end{array}$ & $2 \theta\left(^{\circ}\right)$ & $\begin{array}{c}\text { Interplane } \\
\text { distance, d }(\AA)\end{array}$ & $\begin{array}{c}\text { Lattice } \\
\text { constant, a }(\AA)\end{array}$ & $\begin{array}{c}\text { Volume of cell, } \\
(\AA)^{3}\end{array}$ & $\begin{array}{c}\text { Crystallite size, } \\
\mathrm{D}(\mathrm{nm})\end{array}$ & FWHM \\
\hline$(111)$ & 37.96 & 2.3705 & 4.1058 & 67.330 & 11.68 & 0.7098 \\
$(200)$ & 44.10 & 2.0535 & 4.1070 & 68.63 & & 0.6625 \\
$(220)$ & 62.44 & 1.4524 & 4.1081 & 68.398 & & 0.5205 \\
$(311)$ & 77.50 & 1.3696 & 4.1088 & 68.172 & & 0.2839 \\
\hline
\end{tabular}

in the diffractogram. This phenomenon suggests coreshell formation. The additional peaks in the diffractogram could plausibly mean a presence of phase impurities in the sample or oxidation of nickel to $\mathrm{NiO}$ or $\mathrm{Ni}_{2} \mathrm{O}_{3}$ or $\mathrm{Ni}(\mathrm{OH})_{2}$. The average crystallite size of $11.68 \mathrm{~nm}$ for $\mathrm{d}_{111}$, with an experimental lattice constant $4.0862 \AA$ of $\mathrm{Ag}$ fcc, agrees with the unit cell value, $\mathrm{a}=4.086 \AA$ obtained from Rietveld calculation for Ag fcc phase using FullProf software, where $a_{1}=a_{2}=a_{3}, \alpha, \beta, \gamma=90^{\circ}$, with space group F m - 3 m
(ICDD\#96-900-8460). From the matched phase identification (Fig. 3(b)), Rietveld refinement convergence was also confirmed by FullProf software for the assynthesized Ag NPs. As XRD is unable to differentiate two boundaries, the crystallite size is smaller in size compared with the particle size. The observation is in agreement with a previous study [30]. Table 1 gives detailed structural parameters using the following formulas; the lattice constant, $\mathrm{a},=\mathrm{d} \cdot \sqrt{ } \mathrm{h}^{2}+\mathrm{k}^{2}+\mathrm{l}^{2}$, where 
$\mathrm{d}=$ interplane distance obtained from FullProf software. The volume of unit cell $\mathrm{V}=\mathrm{a}^{3}$ and $\mathrm{D}=\mathrm{k} \lambda / \beta \operatorname{Cos} \theta$, where $\mathrm{D}$ is the crystallite size in $\mathrm{nm}, \mathrm{k}=$ Scherrer's constant $(0.94)$, $\lambda$ is wavelength of incident $X$-ray $=1.5417 \AA, \beta=$ Full width half maximum (FWHM) in radians and $\theta=$ Bragg angle in radian. $2 \theta$ correction $=0.07516^{\circ}$, the phase match displays specimen displacement correction (Bragg Brentano geometry) $\mathrm{T}=(\mathrm{s} / \mathrm{R})=0.0026336$, wavelength $=1.541874 \AA$.

A representation of the TEM image and histogram showing the particle size distribution of the Ag NPs prepared using N. tabacum as a reductant is presented in Fig. 4. The TEM micrograph shows irregular shapes and different orientations with discontinuity in the grain boundary of Ag nanoparticles. The TEM micrograph of Ag NPs reveals a quasi-cube shaped nanoparticle with an average size of $19.14 \pm 6.43 \mathrm{~nm}$ (using Image J software). Quantified elemental composition analysis also supports the formation of Ag NPs, as shown in the EDX analysis. The as-prepared Ag NPs are dominated by silver (89.11 wt.\%), oxygen (3.99 wt.\%) and carbon (4.78 wt.\%) originated from the plant extract (See supplementary Table, S3).
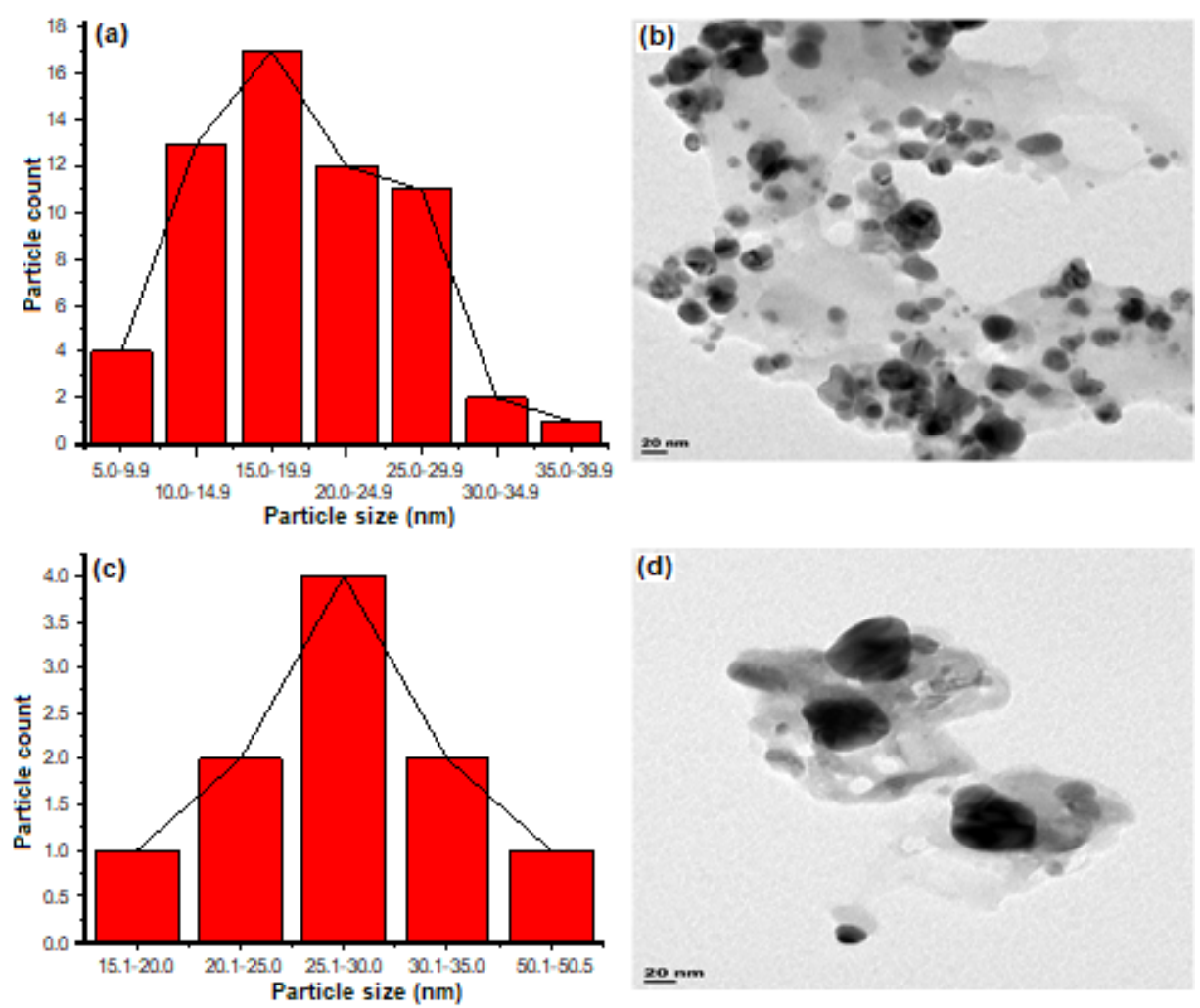

Fig 4. Particle size distribution histograms of (a) Ag NPs (c) Ag-Ni nanoparticles, and representative TEM images of (b) Ag NPs (d) Ag-Ni NPs 
Phytochemical screening of the aqueous extract of the Nicotiana tabacum indicated the presence of alkaloids, carbohydrates, and glycosides (Table 2). Water was chosen as the solvent medium following the principle of green chemistry. A qualitative study using FTIR spectroscopy revealed the moieties adsorbed on the surface of the asprepared nanoparticles (Fig. 5), which were also responsible for the capping and stability of the nanomaterials [32]. Some characteristic peaks with frequency at $3274 \mathrm{~cm}^{-1}$ assigned to $\mathrm{N}-\mathrm{H}$ stretching of amine group were present in the alkaloid, which acted as the bio-reducing agent. Other prominent peaks includethe peaks at $2935 \mathrm{~cm}^{-1}$ (C-H stretching from $\mathrm{SP}^{3}$ hybridization), $1641 \mathrm{~cm}^{-1}(\mathrm{C}=\mathrm{C}$ stretching), $1534 \mathrm{~cm}^{-1}$ (C=N stretching), $1228 \mathrm{~cm}^{-1}(\mathrm{C}-\mathrm{N}$ of amine or $\mathrm{C}-\mathrm{O}$ stretching) that were detected from the phytochemical analysis (Table 4).

The proposed biosynthesis reaction took place through the active sites created by nitrogen present in the alkaloids of $N$. tabacum, resulting in the attachment of methylene groups to nitrogen on the surface of the Ag nanoparticles as proposed in our earlier study [33]. There appears to be no peak in the carbonyl $(\mathrm{C}=\mathrm{O})$ region characteristic of carbohydrates and glycosides (Scheme
1). This observation is different from the phytoconstituents present in the Senna occidentalis plant as reported in a previous work [34]. The observed $\mathrm{C}-\mathrm{O}$ stretch is weak, which indicates more alkaloids in the tobacco plant. Hence, the proposed mechanism of reaction suggests the reduction of $\mathrm{Ag}^{+}$ions to $\mathrm{Ag}^{0}$ and $\mathrm{Ni}^{2+}$ to $\mathrm{N}^{0}$ could be due to abundant alkaloids in the plant extract. This observation is similar to the findings by Shekins et al. [35].

Table 2. Phytochemical constituents of Nicotiana tabacum leaf extract

\begin{tabular}{lc}
\hline Biochemical & Water extract \\
\hline Proteins & - \\
Alkaloids & + \\
Saponins & - \\
Carbohydrates & + \\
Phenols & - \\
Tannins & - \\
Glycosides & + \\
Flavonoids & - \\
Terpenoids & - \\
Steroids & - \\
\hline + Present - Absent &
\end{tabular}

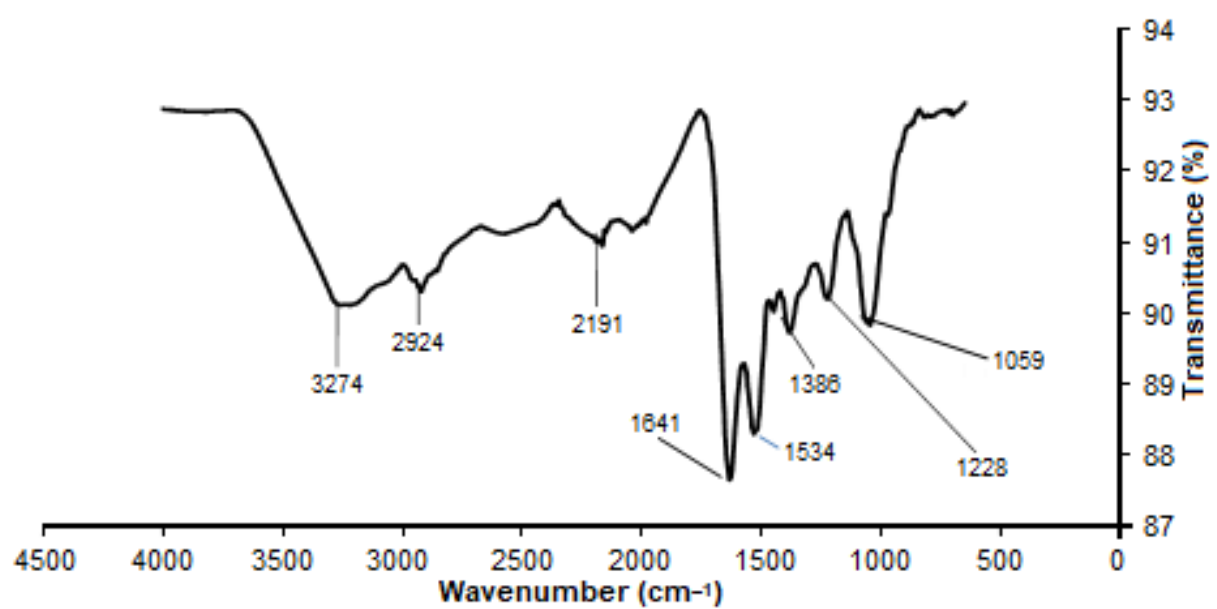

Fig 5. FTIR spectrum of Ag-NPs using the extract of Nicotiana tabacum<smiles>CN1CCCC1c1cncc(N2CCCC2c2cncc(N=[N+]=[N-])c2)c1</smiles>

Scheme 1. Proposed reduction reaction mechanism by alkaloids [36] 


\section{Antimicrobial Assay}

From the measured zones of inhibition displayed by the Ag NPs prepared by using N. tabacum, the activity of Ag NPs was revealed. Preliminary screening of Ag NPs (agar diffusion test) showed that the nanocluster exhibited moderate activities on all organisms except $P$. aeruginosa, where comparatively low activity was recorded (Table 3 ). However, the result of statistical analysis (ANOVA and SPSS) indicated there was no significant difference at the two precursor concentrations when $\mathrm{P}>0.05$. When compared with the standard, the activity of Ag NPs on the organisms was similar at concentrations of 2.0 and $3.0 \mathrm{mM}$. These observations led to the susceptible antimicrobial testing MIC, MFC, and MBC.

From Table 3, it is shown that higher activity was observed in Ag NPs prepared with $3.0 \mathrm{mM}$ precursor concentration. Streptococcus pyogenes (Gram-positive bacterium), a human pathogen responsible for acute infections like pharyngitis, was the most susceptible species to the nanoparticles [37]. This sensitivity could be a result of the large volume of surface area possessed by nanoparticles, as this fostered more contact and interaction with cells [38]. Our result is different from the findings by Sarwar et al. [39] and Domínguez et al. [40], in which Gram-negative bacteria were more susceptible to nanoparticles compared to Gram-positive bacteria. This could be attributed to the nature of the cell wall found in Gram-negative bacteria, which is composed of phospholipids, lipoprotein, and thin lipopolysaccharides. However, S. pyogenes had the highest susceptibility to the as-prepared Ag NPs, that could be attributed to the component structure on the bacteria cell. A lot of pores and teichoic acid have been reported to be present in Gram-positive bacteria, which allow the infiltration of foreign molecules, thereby causing damage to the cell membrane or even killing it. It could also be possible that the Ag NPs could not adhere to the negatively-charged peptidoglycan layer organized on the organism, thereby permitting the penetration of the nanoparticles [16]. The same MIC and MBC (least concentration) of $12.5 \mathrm{mg} / \mathrm{mL}$ observed was an indication that the nanoparticles were bactericidal. In order of sensitivity, Streptococcus pyogenes was followed by Staphylococcus aureus (Grampositive bacterium) and a fungus - Candida albicans, with the same MIC and MFC concentrations of $12.5 \mathrm{mg} / \mathrm{mL}$ and $25 \mathrm{mg} / \mathrm{mL}$, respectively. S. aureus is usually found on the skin and upper respiratory tract of individuals [41].

Other organisms were less sensitive to the Ag NPs compared to Streptococcus pyogenes. The observed activity of Ag NPs against E. coli was at MIC concentration of $25 \mathrm{mg} / \mathrm{mL}$, which is the same value for MBC as well. In the case of Trichophyton rubrum, the nanocluster was active at $25 \mathrm{mg} / \mathrm{mL}$ MIC and $50 \mathrm{mg} / \mathrm{mL}$ MFC concentrations. Least activity was detected in the Gram-negative bacterium - Pseudomonas aeruginosa. This pathogen that causes chronic infections in the urinary tract, surgical wounds, and the respiratory tract was sensitive to the Ag NPs at the same MIC and MBC concentration of $50 \mathrm{mg} / \mathrm{mL}$.

In contrast, no activity was found on P. aeruginosa by Ag NPs prepared with $2.0 \mathrm{mM}$ metal precursor (Table 4). This experimental insensitivity could be due to the high negatively-charged lipopolysaccharides on the cell wall of $P$. aeruginosa, protecting the cell membrane [42].

Table 3. Sensitivity testing of organisms with standard deviation in zones of inhibition (Agar Diffusion Test)

\begin{tabular}{ccccccc}
\hline Nanoparticles & \multicolumn{5}{c}{ Organisms/Mean zone diameter $(\mathrm{mm}) \pm \mathrm{SD}$} \\
\cline { 2 - 7 } & $\begin{array}{c}\text { Staphylococcus } \\
\text { aureus }\end{array}$ & $\begin{array}{c}\text { Streptococcus } \\
\text { pyogenes }\end{array}$ & $\begin{array}{c}\text { Escherichia } \\
\text { coli }\end{array}$ & $\begin{array}{c}\text { Pseudomonas } \\
\text { aeruginosa }\end{array}$ & $\begin{array}{c}\text { Candida } \\
\text { albicans }\end{array}$ & $\begin{array}{c}\text { Trichophyton } \\
\text { rubrum }\end{array}$ \\
\hline Ag 2.0 & $10 \pm 0.5$ & $11 \pm 0.5$ & $9 \pm 0.2$ & $7 \pm 0.1$ & $10 \pm 0.2$ & $9 \pm 0.3$ \\
Ag 3.0 & $12 \pm 0.3$ & $13 \pm 0.5$ & $10 \pm 0.5$ & $9 \pm 0.1$ & $12 \pm 0.1$ & $10 \pm 0.5$ \\
Control & $21 \pm 0.8$ & $18 \pm 0.3$ & $21 \pm 0.2$ & $20 \pm 0.4$ & $19 \pm 0.6$ & $18 \pm 0.3$ \\
STAT & $\boldsymbol{P}>\mathbf{0 . 0 5}$ & $\boldsymbol{P}>\mathbf{0 . 0 5}$ & $\boldsymbol{P}>\mathbf{0 . 0 5}$ & $\boldsymbol{P}>\mathbf{0 . 0 5}$ & $\boldsymbol{P}>\mathbf{0 . 0 5}$ & $\boldsymbol{P}>\mathbf{0 . 0 5}$ \\
\hline
\end{tabular}

Standard/Control = Ciprofloxacin (Bacteria) and Fluconazole (Fungi). Ag 2.0 = Silver nanoparticles prepared from $2.0 \mathrm{mM}$ precursor concentration using N. tabacum leaf extract. Ag 3.0 = Silver nanoparticles prepared from $3.0 \mathrm{mM}$ precursor concentration using $\mathrm{N}$. tabacum leaf extract 
Table 4. Minimum inhibitory concentration (MIC), minimum bactericidal concentration (MBC) and minimum fungicidal concentration (MFC)

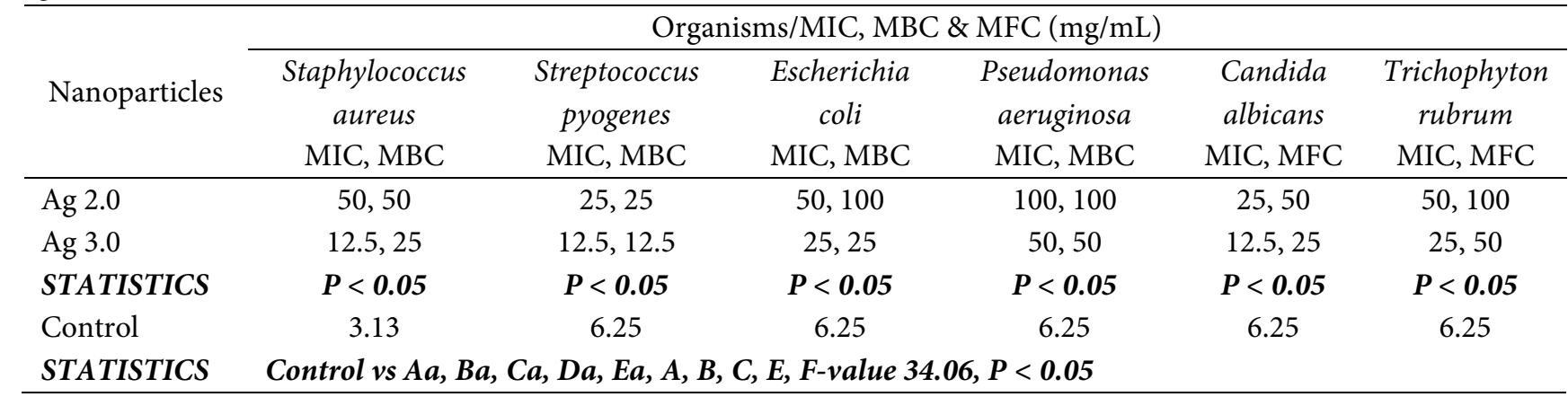

Control- Ciprofloxacin (Bacteria) and Fluconazole (Fungi)

The activity of Ag NPs was lower compared to ciprofloxacin and fluconazole (standards). However, a oneway analysis of variance using SPSS tool proved that the growth inhibition by Ag NPs was significant at $\mathrm{P}<0.05$.

\section{- CONCLUSION}

This work has explored the possibilities and better utilization of N. tabacum. The known addictive plant used for smoking was converted into monometallic and bimetallic nanoparticles. From UV-visible spectroscopy, it was shown that the nanoparticles possess optical properties with the appearance of surface plasmon resonance at $438 \mathrm{~nm}$ for Ag NPs, and broad peakbroadening in the $\mathrm{Ag}_{\text {core }} \mathrm{Ni}_{\text {shell }}$ nanohybrid that was formed. SPR bands formed in the Ag-Ni nanohybrid had lower extinction coefficient intensity with peak widthbroadening, compared to the corresponding Ag NPs. Photoluminescence study revealed low emission potential in Ag NPs. TEM, EDX, XRD, and FTIR characterizations supported the formation of $\mathrm{Ag}$ and $\mathrm{Ag}-\mathrm{Ni}$ hybrid nanoparticles. Ag NPs prepared from $3.0 \mathrm{mM}$ metal nanoparticles have proven to overcome the challenge of biofilm formation in drug resistance. Ag NPs displayed the highest activity against the clinically isolated Streptococcus pyogenes, Gram-positive bacterium, with $12.5 \mathrm{mg} / \mathrm{mL}$ MIC and MBC value, followed by Staphylococcus aureus (Gram-positive bacterium) and a fungus - Candida albicans, with the same MIC and MFC concentrations of $12.5 \mathrm{mg} / \mathrm{mL}, 25 \mathrm{mg} / \mathrm{mL}$, respectively. The lower sensitivity of Ag NPs was observed against E. coli and Trichophyton rubrum with the same MIC and MBC concentration of
$25 \mathrm{mg} / \mathrm{mL}$ and. The $\mathrm{Ag}$ nanoparticle was active at $25 \mathrm{mg} / \mathrm{mL}$ MIC concentration, and $50 \mathrm{mg} / \mathrm{mL}$ MFC concentration. No activity was noticed against $P$. aeruginosa by Ag NPs prepared with $2.0 \mathrm{mM}$ metal precursor. Finally, ANOVA statistical tool that was used to validate the growth inhibition of Ag NPs showed that it was significant at $\mathrm{P}<0.05$. From this study, Ag NPs prepared from Nicotiana tabacum was proven to be a possible candidate for developing antibacterial and antifungal drugs.

\section{- ACKNOWLEDGMENTS}

The authors acknowledge Oluwaseun Ejilude of Sacred Heart Hospital, Nigeria, for the antimicrobial assay. We would also like to thank Mr. Shitole Joseph of iThemba Labs, South Africa, for the morphology characterization. Covenant University is appreciated for supporting this publication.

\section{- SUPPORTING INFORMATION}

Additional figures, tables, and data are available in the supplementary material.

\section{- AUTHOR CONTRIBUTIONS}

EO Dare designed the research, A.A. Akinsiku conducted the experiment and wrote the manuscript. J.A. Adekoya revised the manuscript.

\section{- REFERENCES}

[1] Nasrollahzadeh, M., Sajjadi, M., Sajadi, S.M., and Issaabadi, Z., 2019, "Green nanotechnology" in $A n$ 
Introduction to Green Nanotechnology, Volume 28, Academic Press, London, 145-198.

[2] Sathishkumar, P., Vennila, K., Jayakumar, R., Yusoff, A.R.M., Hadibarata, T., and Palvannan, T., 2016, Phyto-synthesis of silver nanoparticles using Alternanthera tenella leaf extract: An effective inhibitor for the migration of human breast adenocarcinoma (MCF-7) cells, Bioprocess Biosyst. Eng., 39 (4), 651-659.

[3] Michna, A., Morga, M.M., Adamczyk, Z., and Kubiak, K., 2019, Monolayers of silver nanoparticles obtained by green synthesis on macrocation modified substrates, Mater. Chem. Phys., 227, 224-235.

[4] Oyekunle, I.P., Nwogu, U.S., Orababa, O.Q., Nsude, C.C., Ikpa, J.O., and Azuka, D.C., 2019, Phytochemical, antimicrobial, and proximate composition of Nicotiana tabacum leaves extract, IJISRT, 4 (5), 406-410.

[5] Adeniyi, P.A.O., Ghazal, O.K., Musa, A.A., and Caxton-Martins, E.A., 2010, The neurobehavioural effects of smoke and ethanolic extract of Nicotiana tabacum leaves exposure in mice, Res. J. Anim. Sci, 4 (4), 99-102.

[6] Ningthoujam, S.S., Talukdar, A.D., Potsangbam, K.S., and Choudhury, M.D., 2013, Traditional uses of herbal vapour therapy in Manipur, North-East India: An ethnobotanical survey, J. Ethnopharmacol., 147 (1), 136-147.

[7] Fongnzossie, E.F., Tize, Z., Nde, P.J.F., Biyegue, C.F.N., Ntsama, I.S.B., Dibong, S.D., and Nkongmeneck, B.A., 2017, Ethnobotany and pharmacognostic perspective of plant species used as traditional cosmetics and cosmeceuticals among the Gbaya ethnic group in Eastern Cameroon, S. Afr. J. Bot., 112, 29-39.

[8] Smith, R.A., Andrews, K.S., Brooks, D., Fedewa, S.A., Manassaram-Baptiste, D., Saslow, D., Brawley, O.W., and Wender, R.C., 2018, Cancer screening in the United States, 2018: A review of current American Cancer Society guidelines and current issues in cancer screening, CA Cancer J. Clin., 68 (4), 297-316.

[9] Massironi, A., Morelli, A., Grassi, L., Puppi, D., Braccini, S., Maisetta, G., Esin, S., Batoni, G., Pina,
C.P., and Chiellini, F., 2019, Ulvan as novel reducing and stabilizing agent from renewable algal biomass: Application to the green synthesis of silver nanoparticles, Carbohydr. Polym., 203, 310-321.

[10] Tripathi, D., Modi, A., Narayan, G., and Rai, S.P., 2019, Green and cost effective synthesis of silver nanoparticles from endangered medicinal plant Withania coagulans and their potential biomedical properties, Mater. Sci. Eng., C, 100, 152-164.

[11] Parthiban, E., Manivannan, N., Ramanibai, R., and Mathivanan, N., 2019, Green synthesis of silvernanoparticles from Annona reticulata leaves aqueous extract and its mosquito larvicidal and anti-microbial activity on human pathogens, Biotechnol. Rep., 21, e00297.

[12] Baláž, M., Daneu, N., Balážová, L., Dutková, E., Tkáčiková, L., Briančin, J., Vargová, M., Balážová, M., Zorkovská, A., and Baláž, P., 2017, Biomechanochemical synthesis of silver nanoparticles with antibacterial activity, Adv. Powder Technol., 28 (12), 3307-3312.

[13] Akinsiku, A.A., Dare, E.O., Ajani, O.O., Ayo-Ajayi, J., Ademosun, O.T., and Ajayi, S.O., 2018, Room temperature phytosynthesis of $\mathrm{Ag} / \mathrm{Co}$ bimetallic nanoparticles using aqueous leaf extract of Canna indica, IOP Conf. Ser.: Earth Environ. Sci., 173, 012019.

[14] Mohammadi, M.M., Gunturi, S.S., Shao, S., Konda, S., Buchner, R.D., and Swihart, M.T., 2019, Flamesynthesized nickel-silver nanoparticle inks provide high conductivity without sintering, Chem. Eng. J., 372, 648-655.

[15] Pinkas, J., Sopoušek, J., Brož, P., Vykoukal, V., Buršik, J., and Vřeštal, J., 2019, Synthesis, structure, stability and phase diagrams of selected bimetallic silver- and nickel-based nanoparticles, Calphad, 64, 139-148.

[16] Vykoukal, V., Bursik, J., Roupcova, P., Cullen, D.A., and Pinkas, J., 2019, Solvothermal hot injection synthesis of core-shell AgNi nanoparticles, J. Alloys Compd., 770, 377-385.

[17] Wang, L., Hu, C., and Shao, L., 2017, The antimicrobial activity of nanoparticles: Present 
situation and prospects for the future, Int. J. Nanomed., 12, 1227-1249.

[18] Akinsiku, A.A., Ajanaku, K.O., Adekoya, J.A., and Dare, E.O., 2015, Green synthesis, characterization of silver nanoparticles using Canna indica and Senna occidentalis leaf extracts, Proceedings of $2^{\text {nd }}$ Covenant University - International Conference on African Development Issues 2015 (CU-ICADI 2015), 154-157.

[19] Gul, R., Jan, S.U., Faridullah, S., Sherani, S., and Jahan, N., 2017, Preliminary phytochemical screening, quantitative analysis of alkaloids, and antioxidant activity of crude plant extracts from Ephedra intermedia indigenous to Balochistan, Sci. World J., 2017, 5873648.

[20] White, A.R., 2008, The British Society for Antimicrobial Chemotherapy Resistance Surveillance Project: A successful collaborative model, J. Antimicrob. Chemother., 62 (Suppl. 2), ii3ii14.

[21] Kiehlbauch, J.A., Hannett, G.E., Salfinger, M., Archinal, W., Monserrat, C., and Carlyn, C., 2000, Use of the National Committee for Clinical Laboratory Standards guidelines for disk diffusion susceptibility testing in New York State Laboratories, J. Clin. Microbiol., 38 (9), 3341-3348.

[22] Portillo, A., Vila, R., Freixa, B., Adzet, T., and Cañigueral, S., 2001, Antifungal activity of Paraguayan plants used in traditional medicine, $J$. Ethnopharmacol., 76 (1), 93-98.

[23] Clinical and Laboratory Standards Institute, 2020, Performance standards for antimicrobial susceptibility testing, $30^{\text {th }}$ Ed., CLSI supplement M100, Clinical and Laboratory Standards Institute, Wayne, PA.

[24] Mostafa, A.A., Al-Askar, A.A., Almaary, K.S., Dawoud, T.M., Sholkarny, E.N., and Bakri, M.M., 2018, Antimicrobial activity of some plant extracts against bacterial strains causing food poisoning diseases, Saudi J. Biol. Sci., 25 (2), 361-366.

[25] Nasrollahzadeh, M., Sajadi, S.M., Babaei, F., and Maham, M., 2015, Euphorbia helioscopia Linn as a green source for the synthesis of silver nanoparticles and their optical and catalytic properties, J. Colloid Interface Sci., 450, 374-380.

[26] Fernando, I., and Zhou, Y., 2019, Impact of pH on the stability, dissolution and aggregation kinetics of silver nanoparticles, Chemosphere, 216, 297-305.

[27] Panariello, L., Mazzei, L., and Gavriilidis, A., 2018, Modelling the synthesis of nanoparticles in continuous microreactors: The role of diffusion and residence time distribution on nanoparticle characteristics, Chem. Eng. J., 350, 1144-1154.

[28] Kumar, M., and Deka, S., 2014, Multiply twinned AgNi alloy nanoparticles as a highly active catalyst for multiple reductions and degradation reactions, ACS Appl. Mater. Interfaces, 6 (18), 16071-16081.

[29] Adekoya, J.A., Dare, E.O., Mesubi, M.A., and Revaprasadu, N., 2014, Synthesis and characterization of optically active fractal seedmediated silver nickel bimetallic nanoparticles, $J$. Mater., 2014, 184216.

[30] Mourdikoudis, S., Pallares, R.M., and Thanh, N.T.K., 2018, Characterization techniques for nanoparticles: Comparison and complementarity upon studying nanoparticle properties, Nanoscale, 10 (27), 12871-12934.

[31] Tsuji, M., Hikino, S., Matsunaga, M., Sano, Y., Hashizume, T., and Kawazumi, H., 2010, Rapid synthesis of Ag@Ni core-shell nanoparticles using a microwave-polyol method, Mater. Lett., 64 (16), 1793-1797.

[32] Hashemi, S.F., Tasharrofi, N., and Saber, M.M., 2020, Green synthesis of silver nanoparticles using Teucrium polium leaf extract and assessment of their antitumor effects against MNK45 human gastric cancer cell line, J. Mol. Struct., 1208, 127889.

[33] Akinsiku, A.A., Ajanaku, K.O., Adebisi, A.A., Edobor-Osoh, A., Aladesuyi, O., Taiwo, O.S., and Dare, E.O., 2019, Momordica charantia stem extract mediated biogenic synthesis of silver nanoparticles: Optical and antimicrobial efficacy, IOP Conf. Ser.: Mater. Sci. Eng., 509, 012018.

[34] Akinsiku, A.A., Ajanaku, K.O., and Dare, E.O., 2019, Green synthesis of pseudo-cubic $\mathrm{Ag} / \mathrm{Ni}$ 
bimetallic nanoparticles using Senna occidentalis leaf extract, J. Phys. Conf. Ser., 1299, 012133.

[35] Shekins, O.O., Dorathy, E.U., Labaran, M.L., and Joel, P., 2016, Phytochemical screening of tobacco (Nicotiana tabacum) and its effects on some haematological parameters and histopathology of liver and brain in male rats, Int. J. Biochem. Res. Rev., 14 (4), 1-9.

[36] Akinsiku, A.A., Dare, E.O., Ajanaku, K.O., Ajani, O.O., Olugbuyiro, J.A.O., Siyanbola, T.O., Ejilude, O., and Emetere, M.E., 2018, Modeling and synthesis of $\mathrm{Ag}$ and $\mathrm{Ag} / \mathrm{Ni}$ allied bimetallic nanoparticles by the green method: Optical and biological properties, Int. J. Biomater., 2018, 9658080.

[37] Bryant, A.E., and Stevens, D.L., 2015, "Streptococcus pyogenesin" in Mandell, Douglas, and Bennett's Principles and Practice of Infectious Diseases, $8^{\text {th }}$ Ed., Eds. Bennet, J.E., Dolin, R., and Blaser, M.J., Elsevier Saunders, Philadelphia, PA, 2285-2299.

[38] Huh, A.J., and Kwon, Y.J., 2011, "Nanoantibiotics": A new paradigm for treating infectious diseases using nanomaterials in the antibiotics resistant era, $J$. Controlled Release, 156 (2), 128-145.

[39] Sarwar, A., Katas, H., Samsudin, S.N., and Zin, N.M., 2015, Regioselective sequential modification of chitosan via azide-alkyne click reaction: Synthesis, characterization, and antimicrobial activity of chitosan derivatives and nanoparticles, PLoS One, 10, (4), e0123084.

[40] Domínguez, A.V., Algaba, R.A., Canturri, A.M., Villodres, A.R., and Smani, Y.Y., 2020, Antibacterial activity of colloidal silver against Gram-negative and Gram-positive bacteria, Antibiotics, 9 (1), 36.

[41] Zhang, L., Hou, L., Zhang, S., Kou, X., Li, R., and Wang, S., 2020, Mechanism of S. aureus ATCC 25923 in response to heat stress under different water activity and heating rates, Food Control, 108, 106837.

[42] Dakal, T.C., Kumar, A., Majumdar, R.S., and Yadav, V., 2016, Mechanistic basis of antimicrobial actions of silver nanoparticles, Front. Microbiol., 7, 1831. 